\title{
Pronunciamiento del Directorio de la Sociedad Chilena de Obstetricia y Ginecología sobre el proyecto ley que regula la despenalización de la interrupción voluntaria del embarazo en tres causales
}

Se discute en el parlamento chileno un proyecto de ley enviado por el ejecutivo, que busca despenalizar la interrupción voluntaria del embarazo en tres causales: peligro de la vida de la mujer embarazada, embrión o feto que padezca una alteración estructural congénita incompatible con la vida extrauterina y embarazo producto de una violación.

Muchas personas y diversos grupos han manifestado su opinión sobre este tema, apoyando o rebatiendo la pertinencia del cuerpo legal, intentando llevar tanto la discusión como el curso de la ley en la dirección que les parece más propicia a sus valores y convicciones. Dada la enorme importancia del tema tanto para la especialidad como para el país, la Sociedad Chilena de Obstetricia y Ginecología (SOCHOG) quiere ser una entidad activa desde el punto de vista de su contribución a la investigación científica, como también velar porque el proyecto de ley antes mencionado, contemple y resguarde de manera eficaz la objeción de conciencia de cada médico frente a la compleja decisión de realizar o no un aborto, una problemática de sumo compleja, que no solo tiene implicancias médicas/científicas, sino también éticas y filosóficas, que se relacionan por ejemplo con diferentes concepciones sobre el inicio de la vida, el momento en que se otorga dignidad de persona a un embrión o feto, y el límite de los derechos reproductivos de la mujer.

SOCHOG, en su calidad de "entidad científica" no se pronunciará respecto a este proyecto de ley desde el punto de vista valórico, dada la imposibilidad de aunar los criterios de sus 695 miembros distribuidos por todo el país o su Directorio formado por 9 representantes elegidos en votación directa; todos y cada uno de los cuales poseen diversas convicciones morales, posturas, creencias éticas o religiosas. Hacemos sin embargo, una invitación extensiva a todos los médicos de nuestra asociación para reflexionar en conciencia sobre este proyecto de ley. Los médicos socios o los directores, en cuanto personas, pueden y deben manifestar su opinión, a título personal, y de hecho muchos ya lo han hecho con cartas a los diarios o creación de grupos especiales para la defensa de una $u$ otra opinión, lo que refuerza la idea de que la participación de los gineco-obstetras en el debate, es interesante e indispensable.

La SOCHOG es una sociedad científica, cuyos objetivos están claramente explicitados (http:// www.sochog.cl/objetivos.php):

- Promover, auspiciar, patrocinar, organizar y celebrar, por cuenta propia o ajena, reuniones científicas periódicas, congresos, cursos de perfeccionamiento académico, jornadas de estudio, simposios, mesas redondas, seminarios, conferencias y todas las demás actividades destinadas al estudio, la reflexión, la investigación y el avance de sus especialidades.

- Concurrir a la creación o participar en otras corporaciones, fundaciones, organizaciones no gubernamentales o en cualquier otra persona jurídica de derecho privado o público, sin fines de lucro, cuyos objetivos estén relacionados con la ginecología u obstetricia.

- Realizar publicaciones periódicas o no periódicas, sobre materias relacionadas con sus especialidades y, especialmente, velar por la excelencia de la publicación denominada Revista Chilena de Obstetricia y Ginecología.

- En general, realizar todas las actividades relacionadas o complementarias a sus objetivos específicos.

Creemos que SOCHOG tiene un rol activo en el debate sobre este proyecto y también en la materialización de la ley, pero siempre desde un punto de vista científico, estudiando por ejemplo las consecuencias de la despenalización del aborto en base a información publicada y analizada desde una perspectiva epidemiológica y médica, dimensionando entre otros aspectos el número de casos 
al año en que un aborto por enfermedad materna pueda discutirse; estableciendo las potenciales causas fetales que limitan la vida extrauterina y en cuanto la limitan. Definiendo los efectos en la salud física y mental de una mujer, provocados por un embarazo resultante de una violación y como estos cambian en cuanto se efectúa o no un aborto. Asumimos como propias estas y otras interrogantes científicas relacionadas que sería imposible mencionar brevemente en este editorial.

Para cumplir con estos requerimientos científicos hemos recurrido a esta importante tribuna para establecer el marco en el cual nos manifestaremos sobre el proyecto de ley antes mencionado. Durante las próximas semanas enviaremos para consideración en la Revista Chilena de Obstetricia y
Ginecología, artículos de revisión sistemática que constituyan herramientas de discernimiento para nuestros médicos y la comunidad científica en general, y que sirvan como un aporte al debate nacional, y de igual forma les haremos llegar a nuestros asociados una encuesta para conocer directamente sus opiniones en estos temas.

Expresarse desde una perspectiva valórica sobre este $u$ otros temas de interés nacional, es complejo para SOCHOG o su Directorio por dos razones fundamentales: la primera, que sus estatutos apuntan a una línea científica y la segunda que es imposible representar a todos sus miembros.

Directorio

Sociedad Chilena de Obstetricia y Ginecología 